\title{
A FORMAÇÃO DO PENSAMENTO TEÓRICO NO ENSINO DESENVOLVIMENTAL: CONTRIBUIÇÕES PARA O ENSINO DA QUÍMICA
}

\author{
Andréia Andreóli Silvestre ${ }^{1}$ \\ Sandra Valéria Limonta Rosa²
}

\section{Resumo}

Esta pesquisa se vincula ao Mestrado Interinstitucional em Educação firmado entre o Programa de Pós-Graduação em Educação da UFG e o IFMT, vinculado à Linha de Pesquisa Formação, Profissionalização Docente e Trabalho Educativo e tem como objeto as contribuiçóes da teoria do ensino desenvolvimental para o ensino de Química no Ensino Médio. Partimos do pressuposto de que a função social primordial da escola é o ensino dos conhecimentos acumulados historicamente pela humanidade, sintetizados na Ciência, na Arte e na Filosofia e que esses conhecimentos, sob a forma de conceitos científicos, têm um papel fundamental no processo de desenvolvimento humano. Fundamentando-nos na teoria histórico-cultural do desenvolvimento e na teoria do ensino desenvolvimental de Vassili Vassilievitch Davidov (1982, 1987, 1988, 2003), entendemos que o ensino escolar que promove a aprendizagem e o desenvolvimento é aquele organizado de forma a promover a formaçáo do pensamento teórico dos estudantes. A pesquisa tem como principal objetivo identificar e analisar as contribuiçōes da teoria do ensino desenvolvimental para o ensino de Química no Ensino Médio, buscando compreender os fundamentos pedagógico-didáticos desta teoria por meio da realização de um experimento didático-formativo com alunos do primeiro ano do ensino médio de uma escola estadual da cidade de Cuiabá-MT. A realização do experimento didático-formativo nos permitiu acompanhar e compreender melhor como se dá o complexo processo de aprendizagem dos conceitos científicos, bem como identificar e analisar determinadas contribuições da teoria do ensino desenvolvimental para a organização do ensino

1 Mestra em Educação, técnica em Química do Instituto Federal de Educação Tecnológica de Mato Grosso (IFMT).E-mail: deia.andreoli@gmail.com

2 Pós-doutorado em Educação, professora titular da Universidade Federal de Mato Grosso (UFMT). E-mail: sandralimonta@gmail.com 
de Química. No decorrer do experimento verificamos que houve a formação de um pensamento criativo que foi construído a partir do processo histórico sobre o conteúdo materiais e substâncias, o que caracterizou maior autonomia dos estudantes perante a resolução de situações-problemas e argumentaçôes exigidas na relação do processo ensino-aprendizagem.

Palavras-chave: Ensino de Química. Teoria histórico-cultural. Teoria do ensino desenvolvimental. 


\section{Introdução}

Nossa pesquisa parte do pressuposto de que a escola tem a função social de promover o acesso e a aprendizagem dos conhecimentos historicamente acumulados pela humanidade. Fundamentando-nos em Davidov (1982, $1987,1988,2003)$, acreditamos que o ensino que promove a aprendizagem e se adianta ao desenvolvimento é aquele que busca formar nos estudantes o pensamento teórico.

O ensino escolar atual tem sido muito questionado, não sendo diferente no ensino da Química, que trabalha com muitos modelos teóricos e exige um grande nível de abstração mental por parte dos estudantes, por abordar os conteúdos através de três maneiras: o nível macroscópico, o nível microscópico e o das representaçóes.

Depois da compreensão da problematização do ensino da Química, percebemos que os níveis das representaçóes e o microscópico são os que mais apresentam dificuldade na compreensão dos conceitos, pois estes níveis aparecem relacionados à memorização de fórmulas, equaçóes que não colaboram com a evolução do pensamento dos estudantes, contribuindo para um tipo de pensamento chamado de empírico.

Fundamentando-nos a partir da teoria do ensino desenvolvimental, trouxemos uma proposta de ensino que se contrapóe à problemática acima, de acordo com Davidov (1988), a intenção é propiciar um ensino que promova a aprendizagem, buscando formar nos estudantes o pensamento teórico.

O objetivo geral do nosso trabalho foi identificar e analisar, por meio da realização de um experimento didático, quais as contribuiçóes da teoria do ensino desenvolvimental para o ensino de Química no ensino médio. Já os objetivos específicos visaram à compreensão de descobrir como acontece a aprendizagem dos conceitos científicos na perspectiva da teoria do ensino desenvolvimental, assim como problematizar e analisar o ensino de Química a partir de um panorama das pesquisas sobre essa temática nas produçóes acadêmicas da região Centro-Oeste.

Nossa pesquisa foi estruturada em três capítulos. No Capítulo I, pesquisamos o ensino da Química: história, concepçóes e perspectiva, além da produção acadêmica sobre o ensino de Química na região Centro-Oeste: concepçóes e perspectivas. No capítulo II, mostramos o ensino para o desenvolvimento: fundamentos epistemológicos e pedagógicos para a formação de 
conceitos no ensino de Química. E no capítulo III trouxemos as contribuiçóes da teoria do ensino desenvolvimental para o ensino da Química.

Para este trabalho seria impossível aprofundarmos os três capítulos da dissertação, o que justifica nossa forma de abordagem dando ênfase ao capítulo III, que traz o resultado das contribuiçóes do ensino desenvolvimental para o ensino de Química.

\section{Fundamentos epistemológicos, psicológico e pedagógicos da teoria do ensino desenvolvimental, articulados ao ensino da Química}

O ensino da Química nos permite a compreensão da constituição das propriedades e transformação dos materiais e substâncias, ou seja, os conceitos no ensino da Química são abordados em forma de três aspectos do conhecimento: o fenomenológico, o teórico e o representacional. Nos livros didáticos os conteúdos são abordados através de três maneiras: nível macroscópico, nível microscópico e o das representaçôes, sendo os níveis microscópicos e das representaçóes os que mais apresentam dificuldade no entendimento, em relação ao processo de ensino-aprendizagem.

O nível representacional aparece mais relacionado à memorização das fórmulas, equaçóes e modelos representacionais (muito vistos no ensino da Química). Já o nível microscópico exige dos alunos um alto grau de abstração e construção de modelos mentais, ou seja, uma grande capacidade de articular as ideias. A essas dificuldades enfrentadas no ensino de Química vamos associar um tipo de pensamento chamado de empírico, muito visto em nosso ensino escolar.

Na concepção da teoria do ensino desenvolvimental, Davidov (1988) argumenta que a maioria do ensino escolar tem privilegiado a formação do pensamento empírico. Este tipo de pensamento é considerado importante, porém não precisa de escola para ser formado e se partimos do pressuposto de que a função da escola é promover a formação do pensamento teórico, através dos conhecimentos científicos, devemos incentivar a formação escolar além do pensamento empírico.

Fundamentando-nos a partir da teoria do ensino desenvolvimental, cujo principal representante é Davidov (1988), compreendemos que o ensino que promove a aprendizagem e esta o desenvolvimento é aquele que busca formar 
nos estudantes o pensamento teórico. Davidov (1988) traz uma proposta de ensino que se contrapóe ao modelo de ensino tradicional a que estamos acostumados, ao tipo de formação que favorece a formação do pensamento empírico.

Para Davidov, o bom ensino é aquele em que se adianta ao desenvolvimento, é aquele que ocorre através da internalização das generalizaçóes das ideias, na dialética, ou seja, nas contradiçóes das relaçóes do homem com o mundo, onde o homem transforma a natureza e a si mesmo, provocando várias mudanças. As bases teóricas da nossa pesquisa se originam no materialismo histórico dialético, a partir de Marx, na teoria histórico-cultural (cujo principal representante é Vigotski), até chegarmos à teoria do ensino desenvolvimental.

A teoria histórico-cultural nasce após a Revolução Russa de 1917 (momentos de muitos conflitos na Rússia, entre burguesia, campesinato e proletariado), por volta de 1924. Vigotski (2001) estava insatisfeito com as explicaçôes dadas ao comportamento humano, explicaçóes que associavam estes comportamentos a embasamentos positivistas, pensamentos biologizantes e explicaçóes divinas. Neste contexto nascem as primeiras propostas de Vigotski, através de pesquisas e estudos com a preocupação da criação de uma nova psicologia.

Portanto, a teoria histórico-cultural origina-se com a intenção de superar a ideia de que o ser humano nasce com conjunto de aptidóes e capacidades. Vigotski (2001) iniciou seus estudos sobre comportamento humano e desenvolvimento do psiquismo pelas relaçóes do pensamento, linguagem e consciência, o que ele chamou de funçôes psicológicas superiores, trazendo como pressuposto de que é a existência social que determina a consciência.

Vigotski propôs também pesquisar sobre questôes da aprendizagem escolar, especificamente sobre a formação do pensamento escolar e científico. Para Vigotski (2001), a origem do desenvolvimento psíquico está nas relações entre conceitos científicos e espontâneos, através da linguagem. É por meio dos conceitos científicos que as ideias mais estruturadas vão surgindo, permitindo a formação de generalizações mais amplas e profundas, chegando até o que Vigotski chamou de rede de sistemas de conceitos.

Davidov (1988), na Rússia, entre as décadas de 60 e 70, ao aprofundar os questionamentos de Vigotski, pesquisou as relaçóes entre educação, ensino e desenvolvimento mental e, depois de 25 anos de estudos, traz contribuiçôes para a educação com açóes a serem realizadas na sala de aula, trazendo como intenção principal do ensino, através da aprendizagem, impulsionar o desenvolvimento mental dos estudantes. 
Para Davidov no nosso ensino tradicional o estudante parte do conhecimento particular para o conhecimento geral, sendo guiado pela lógica formal que não traz muita contribuição para a formação do pensamento teórico. De acordo com o ensino desenvolvimental, a lógica formal deve ser substituída pela lógica dialética, com a internalização das ideias vindo de fora para dentro.

A ideia fundamental do ensino desenvolvimental é que os conceitos científicos podem ser assimilados pelos estudantes através de uma atividade de estudo, pela realização coletiva de uma tarefa proposta pelo professor (DAVIDOV, 1988).

Davidov (1988) utiliza a teoria da atividade para embasar sua proposta de ensino na teoria do ensino desenvolvimental e foi em Leontiev (2005), outro colaborador da teoria histórico-cultural, que Davidov buscou mais fundamentação teórica para melhorar sua proposta de ensino. Segundo Leontiev (2005), em cada período da existência humana há uma atividade principal dominante que potencializa o desenvolvimento, por exemplo, na adolescência a atividade guia é o estudo, além de caracterizar a atividade em três componentes estruturais (necessidade, objeto e motivo).

Para Davidov a atividade de estudo fundamentada no ensino desenvolvimental é que deverá impulsionar o desenvolvimento pela transformação do objeto do conhecimento em açóes mentais.

Davidov traz uma proposta metodológica didático-pedagógica desenvolvida por ele, Elkonin e outros colaboradores, a qual o autor denominou de experimento didático ou experimento genético-modelador, que se transformou em uma proposta didática organizada para o ensino escolar, através de tarefas de estudo.

\section{Percurso metodológico: o experimento didático formativo}

O experimento didático que abordamos em nosso trabalho é considerado um plano de ensino intencional, ele foi elaborado através de orientaçóes de autores russos à luz da teoria histórico-cultural sendo estruturada pela teoria do ensino desenvolvimental. Este experimento didático também é chamado de formativo e visou investigar e analisar as mudanças no desenvolvimento do psiquismo, objetivando interferir nas açóes mentais dos estudantes, com a intenção de provocar mudanças em relação ao desenvolvimento mental esperado.

É importante esclarecermos que nossa intenção não é trazer o experimento didático como uma reprodução mecânica do que Davidov e muitos teóricos, 
educadores russos, fizeram ou fazem na Rússia. Seria impossível realizarmos este experimento com esta intenção, a nossa realidade educacional nos permite trazer as contribuiçóes da teoria desenvolvimental com base nas orientaçóes de Davidov, construindo um plano de ensino intencional de acordo com a realidade da nossa educação brasileira.

No início do experimento didático há uma proposta de realização de uma tarefa geral de estudo, em que todas as açóes a serem desenvolvidas precisam estar objetivadas em relação a esta tarefa inicial. É no decorrer desta caminhada, da execução das açóes propostas por Davidov, que se esperam a transformação e desenvolvimento dos estudantes com promoção de mudanças qualitativas através do ensino.

A atividade criativa do professor consiste, precisamente, em atuar em processos de transformação interna dos alunos, ampliando e formando novas ações mentais, uma vez que é por meio delas que uma pessoa lida com os conhecimentos, habilidades, valores, e conquista seu autodomínio. Para isso, é preciso ter conhecimento de duas condiçóes já apontadas: a primeira, a criação nos alunos da necessidade de dominar a herança cultural, esta é a principal condição da atividade de estudo; a segunda, a colocação de tarefas de estudo cuja solução exija deles a experimentação mental visando a transformação criativa do material de estudo a ser assimilado (LIBÂNEO, 2016, p. 366).

A intenção do experimento didático não é apenas resolver problemas, tarefas, como se fosse um passo a passo de açóes, mas compreender que sempre é necessário mobilizar os motivos, as necessidades do estudante para a realização das atividades de estudo. $O$ professor no ato de sua intencionalidade precisa deixar claro que o mais importante não é a realização de problemas, da tarefa ou do experimento. E sim a transformaçáo a ser realizada no decorrer do processo de ensino-aprendizagem, sobre o modo de pensar e agir dos estudantes, provenientes da apropriaçáo dos conteúdos que os estudantes vão constituindo no decorrer das açóes propostas pela atividade de estudo.

O percurso metodológico do nosso trabalho foi a realizaçáo do experimento didático que é caracterizado pela forte interação entre professores e estudantes, no qual os estudantes são incentivados constantemente a participar de forma 
ativa nas aulas de maneira a expressar seus pensamentos. A principal contribuição do experimento didático formativo é transformar o modo de pensar e agir dos estudantes. Para a realização do experimento, Davidov planejou seis açóes organizadas por operaçóes, com a finalidade de se chegar a uma tarefa principal.

$\mathrm{O}$ experimento foi realizado com uma turma de primeiro ano do ensino médio da escola estadual André Luiz da Silva Reis, da cidade de Cuiabá-MT, com média de 26 estudantes presentes. A escolha da turma do primeiro ano para a realização do experimento didático pode ser explicada pelo fato de ser neste momento que os estudantes começam a entrar em contato com conteúdos estruturantes, considerados fundamentais na totalidade do plano de ensino do curso de Química no ensino médio.

O primeiro contato com a turma se deu para aplicação de um questionário socioeconômico e para a entrega dos termos de consentimento para a participação na pesquisa de acordo com o responsável, no qual seguimos as orientaçóes do comitê de ética do IFMT.

O conteúdo escolhido para a realização do experimento foi materiais e substâncias, pois associamos uma das orientações de Davidov (1988) de pensar no "núcleo central" dos conteúdos a serem ensinados, ou seja, nos conceitos essenciais que estruturam outros conceitos dentro da Química.

\section{Desenvolvimento do experimento didático e suas contribuições para o ensino de Química}

De acordo com as orientaçóes de Davidov (1988), o experimento didático formativo deve ser desenvolvido utilizando seis açôes de estudo. Vamos abordar as seis açóes de estudo já trazendo as contribuições do ensino desenvolvimental para o ensino de Química, de acordo com a realização do experimento didático formativo.

Vale ressaltar que, desde o início da realização do experimento, é fundamental o professor mostrar a proposta da tarefa principal $^{3}$ do experimento, conduzindo as açóes sempre frisando a importância da realização de cada ação. Além de mostrar os objetivos de aprendizagem relacionados ao objetivo

3 A tarefa principal consistiu em montar e gravar um minidocumentário de no máximo cinco minutos, explicando sobre, o que os materiais da sua escola são feitos? E quais as substâncias que fazem parte destes materiais? O estudante precisará escolher um material da escola, explicar o conceito de material e investigar quais as substâncias que fazem parte deste material, explicar o conceito, as propriedades e a classificação das substâncias. 
principal do experimento, que é a formação do pensamento teórico sobre o conteúdo materiais e substâncias, trazendo as contribuiçóes do ensino desenvolvimental para o ensino de Química.

A primeira ação de estudo teve como objetivo transformar os termos envolvidos na tarefa de aprendizagem designada e identificar a relação universal do objeto, para os alunos executarem a tarefa, que é conceituar os materiais e substâncias. Nesta ação foram desenvolvidas seis operaçóes e se revelou ser a mais complexa em relação às demais. Tal fato se justifica na importância de identificar e relacionar o que Vigotski (2001) denominou de rede ou pirâmide de conceitos.

A turma foi dividida em três grupos de estudantes, visando facilitar a organização, participação, análises de dados, com o objetivo de transcrever as falas dos estudantes por grupos. $\mathrm{O}$ início da operação 1 teve a intenção de apresentar aos estudantes a história dos conceitos, sendo esta operação fundamental para a formação do pensamento teórico dentro da teoria do ensino desenvolvimental.

Para cumprir com este objetivo foram apresentados aos estudantes dois vídeos, um sobre "o alfabeto da matéria" e o outro sobre "a origem dos alquimistas”. Apesar de alguns problemas estruturais nos equipamentos de exibição dos vídeos, aliados ao tempo da aula, podemos considerar que a operação foi desenvolvida com êxito.

O que é considerado formativo no experimento didático é a maneira da condução e desenvolvimento do experimento didático, não podemos considerá-lo como um passo a passo, ou reprodutivo da mesma maneira que estamos acostumados a ver no ensino tradicional, no qual o professor tem papel ativo na execução das aulas experimentais ou práticas.

Fundamentadas nesta premissa, nós procuramos fazer os questionamentos, através de perguntas e observaçóes com o intuito de levar o estudante a captar as primeiras abstrações necessárias na formação do pensamento teórico. Para este trabalho trouxemos parte do trecho das primeiras abstraçóes:

-Professora: Do que esta mesa, este livro, eu, vocês, seu cabelo, esta parede, do que são feitos?

-Grupo 1: De célula.

-Professora: Mas do que as células são feitas, existe algo além das células? 
-Grupo 1: De ar, de água.

-Professora: Mas o que é matéria?

-Grupo 2: É tudo que tem massa.

A professora continuou questionando, até sair o conceito de que matéria é tudo que tem massa e ocupa lugar no espaço. Porém, os alunos não conseguiram explicar ainda do que a matéria é feita.

-Professora: Como é possível termos tantas frases e palavras com apenas poucas letras no alfabeto brasileiro? A maioria dos alunos ficou quietos, parados, pensando.

-Grupo 1: Elas têm significados, as pessoas aprendem e passam o significado para outras pessoas.

-Grupo 3: Juntando, elas se ligam e formam palavras.

-Aluna Maria: Depois de algum tempo conseguem ser escritas. -Professora: Agora vamos fazer o mesmo raciocínio, vamos pensar para a Química. Como nós temos tantos materiais diferentes? Como é possível? Qual é o alfabeto da matéria? O que o cientista Mendeleiev fez para contribuir com esta ideia? (SILVESTRE, 2017, p. 85).

$\mathrm{Na}$ segunda operação mostramos vários materiais para os estudantes, tais como brincos de cores diferentes; copo com água e copo com álcool; sal e açúcar refinado; e pedimos para eles que identificassem a diferença de um material para o outro, utilizando os sentidos humanos. $\mathrm{O}$ intuito desta operação foi compreender que existe uma propriedade chamada de organoléptica, que ajuda na compreensão das características dos materiais, podendo ser descobertas pelos sentidos humanos.

$\mathrm{Na}$ terceira operação levamos um comprimido efervescente (que são utilizados no combate de acidez estomacal ou má digestáo), e o colocamos em um copo com água, para os alunos observarem o acontecimento e anotarem o que estavam observando. Além do comprimido os alunos observaram brincos, correntes de cores e com tonalidades diferentes com o intuito da verificaçáo do que estava acontecendo com o tempo.

$\mathrm{Na}$ quarta operação, uma chapa de aquecimento foi utilizada para o aquecimento da água juntamente com o auxílio de um termômetro para a anotação 
do valor da temperatura de ebulição, ou seja, a temperatura em que a água começou a ferver. $\mathrm{O}$ mesmo procedimento foi feito para o álcool e depois com o açúcar dissolvido na água, procedimento que exigiu dos estudantes a anotação da temperatura de ebulição pelo termômetro. Esta operação visou à observação de uma característica específica das substâncias.

Este experimento foi prejudicado pelo fato de a escola náo possuir tomada elétrica de 220v, pois a chapa de aquecimento emprestada de outra instituição tinha a voltagem de 220v. Para diminuir o problema o aquecimento da água foi realizado na cozinha da escola, porém esta situação interferiu no valor da temperatura observada pelos estudantes, devido à distância da cozinha até a sala de aula, a temperatura de ebulição da água foi menor do que a esperada. Mesmo com tal situação a professora explicou o imprevisto aos estudantes e fez alguns questionamentos:

-Professora: Quando a água passa do estado líquido para o estado gasoso o que aconteceu? Quando medimos a temperatura da água com o sal dissolvido na água, a temperatura foi diferente? (SILVESTRE, 2017, p. 92).

Apenas o grupo 1 respondeu aos questionamentos, afirmando que a temperatura seria diferente, quando a professora afirmou que uma explicaçáo deveria ser dada pelos estudantes para o fato. $\mathrm{O}$ grupo 2 arriscou a responder pelo fato da mistura das duas substâncias. Diante de tal situação a professora percebeu que muitas dúvidas ainda existiam ante a teoria sobre a caracterização das substâncias e das misturas de substâncias. Nesse momento foi necessário pedir aos estudantes a realização do acompanhamento do livro didático e da leitura, para que eles conseguissem continuar a formação das abstrações iniciais necessárias para a formação do pensamento teórico.

A próxima operação foi mais complexa do que imaginávamos, a intenção foi abordar a densidade das substâncias. Para isso um ovo foi colocado dentro de um copo com água para que os estudantes observassem o que estava acontecendo. Depois o ovo foi retirado do copo e o sal adicionado para que o ovo fosse adicionado novamente, para posterior observação pelos estudantes.

Logo após os procedimentos, nós pedimos para os estudantes a explicação do que havia ocorrido e possível comparação dos resultados. O objetivo desta 
operação foi a compreensão de outra propriedade específica das substâncias, ou seja, a compreensão da densidade.

Depois dos questionamentos feitos pela professora pesquisadora, percebemos que os três grupos de estudantes conseguiram chegar à conclusão de que para descobrir sobre a densidade de uma substância era necessário conhecer a relação massa, volume da substância. Mesmo havendo o conhecimento por parte dos estudantes das informaçóes fundamentais para a compreensão do conceito de densidade, além do sucesso das respostas feitas no caderno de respostas do experimento, percebemos que esse conceito ficou mais no nível empírico do que propriamente no nível do pensamento teórico.

A complexidade do conceito de densidade já é uma das preocupaçôes da área do ensino da Química. Como mostram Rossi et al. (2008), nas aulas de Química, no conteúdo sobre densidade, é dada ênfase mais aos cálculos matemáticos que envolvem o assunto densidade do que a preocupação em ensinar ao estudante a compreensão e resolução de problemas sobre a densidade relacionados aos problemas cotidianos.

A última operação da ação 1 foi uma das mais significativas, mesmo apresentando algumas dificuldades de execução. Esta operação foi realizada entregando duas caixas ${ }^{4}$ por grupos, embrulhadas com papéis de várias cores, as caixas não eram iguais e tinham cores diferentes, dentro delas poderia haver outras caixas. $\mathrm{O}$ intuito desta atividade foi desenvolver o conceito de material, substâncias simples e substâncias compostas e misturas de substâncias e elemento químico.

Os estudantes foram instruídos a descobrir que materiais havia na caixa, no quadro foi colocada a legenda das cores das caixas relacionando com os elementos químicos, para posteriormente descobrir quais substâncias existiam nas caixas e consequentemente quais materiais. Esta operação precisou de mais intervenção por parte da professora pesquisadora do que as outras

4 A atividade com as caixas foi produzida pela professora pesquisadora com o intuito de os estudantes compreenderem o conceito de material, substâncias simples, substâncias compostas, misturas de substâncias e elementos químicos. A professora pregou no quadro um cartaz com a representação das caixas, cada cor das caixas representou um elemento químico. A caixa principal foi encapada com papel de embrulho para presente chamando bem a atenção, dentro dessa caixa havia outras caixas e dentro dessas podia haver outras ou não. As outras caixas foram encapadas por cores diferentes, cada caixa representou a ideia da classificação das substâncias e dos elementos químicos de acordo com as cores que foram encapadas e de acordo com a legenda apresentada pela professora. Como num quebra-cabeça, o grupo deveria representar uma determinada substância química pela fórmula a partir do conjunto de caixas que pegou (SILVESTRE, 2017, p. 96). 
operaçôes, pois, além da agitação dos estudantes ao pegar as caixas, houve confusão e dúvida quanto à realização da atividade (SILVESTRE, 2017).

$\mathrm{O}$ momento em que a professora pesquisadora utilizou por mais tempo o quadro na sala de aula foi nesta operação. Por mais que os estudantes já houvessem avançado nas primeiras abstraçóes partindo do pensamento abstrato chegando ao pensamento concreto, precisavam de entendimento para a trajetória do pensamento teórico sobre como os materiais são formados, sobre sua classificação e representação, portanto não bastava utilizar somente o visual em fórmulas, como é muito visto em nosso ensino tradicional.

Nesta operação evidenciamos o caminho inverso ao qual estamos acostumados a observar no ensino tradicional, é comum nos livros verificarmos a trajetória de pensamento para o conteúdo material e substâncias, partindo da visualizaçáo de fórmulas e classificação, ou seja, do conhecimento particular para depois ir para o geral, guiado pela lógica formal.

Para Davidov (1988), no ensino desenvolvimental a lógica formal deve ser superada pela lógica dialética, pelas relaçôes sociais com a internalização das ideias sendo construídas de fora para dentro, o que justifica a proposta de uma atividade de estudo, através da realização coletiva pelos estudantes proposta pelo professor. A atividade das caixas nos fez percorrer um novo caminho, partimos do pensamento geral de material, substâncias pela relação com os elementos químicos, até chegar-se ao pensamento particular, ou seja, até a representação da fórmula.

Depois de vários questionamentos e incentivo à participação dos estudantes, sempre os levando a pensar no caminho da formação teórica, partindo do pensamento geral para se chegar ao particular, foi possível observar a compreensão dos estudantes sobre as propriedades e características dos materiais e substâncias, cujos conceitos são considerados chaves na identificação da relação universal do conceito geral desses conteúdos.

Depois de percorrermos as seis operaçóes da ação 1, iniciamos a proposta da ação 2, que visou modelar a relação encontrada do conteúdo em forma objetivada. A proposta desta ação teve como objetivo da aprendizagem elaborar um modelo que representasse a ideia de material, substâncias, substâncias simples e substâncias compostas. Os estudantes deveriam criar um modelo para representar a ideia que eles têm sobre material e substâncias.

Para tal representação a ideia inicial deveria partir das substâncias que existem na escola, realizada em grupo e com ajuda da professora, utilizando 
símbolos ou imagens (bolinhas, quadrados, triângulos, pontos, cruz, cores alternadas) para representar a ideia de substâncias simples, substâncias compostas e misturas de substâncias. Na figura abaixo, vamos observar os modelos criados pelos três grupos de estudantes que realizaram o experimento didático:

Figura 1 - Modelação do grupo 1 e 2, acima, respectivamente, e modelação do grupo 3, abaixo, sobre a ideia de material e substâncias

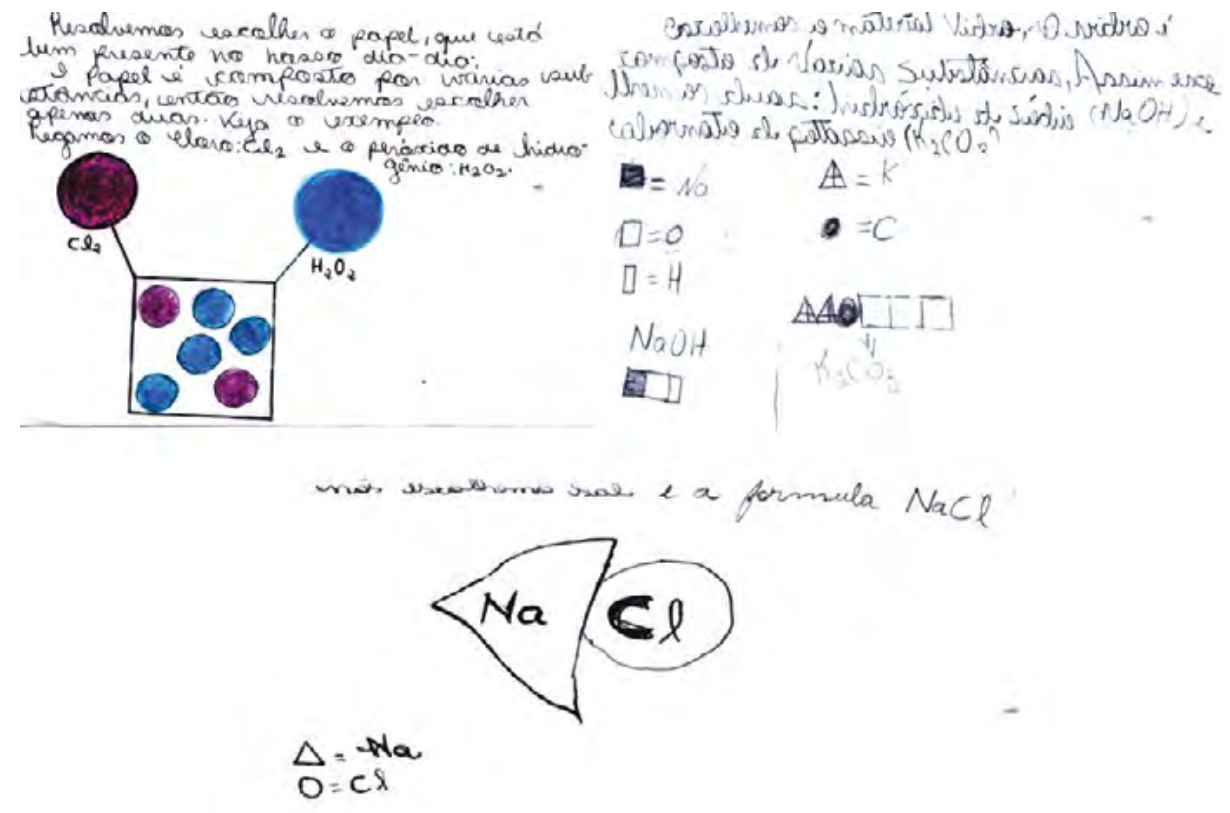

Fonte: SILVESTRE, 2017, p. 99-101.

De acordo com a figura 1, conforme o resultado da ação 2 do experimento didático, os grupos de estudantes escolheram representar o papel (grupo 1), o vidro (grupo 2) e o sal (grupo 3). Analisando a modelação criada pelos estudantes, podemos dizer que, apesar da dificuldade em representar um modelo, os três grupos conseguiram representar a formação do pensamento teórico. A dificuldade maior enfrentada nesta ação foi a não representação de material, um grupo apenas conseguiu representar as substâncias fazendo parte do material. Mesmo com essa dificuldade todos os grupos conseguiram mostrar a diferença de cada elemento químico presente na substância, formando e caracterizando uma substância diferente (SILVESTRE, 2017). 
Para a ação 3, a proposta foi a transformação do modelo com vista a estudar as propriedades intrínsecas do conteúdo. O objetivo da aprendizagem desta ação teve como intuito identificar as propriedades fundamentais para a formação do conceito nuclear do que é matéria e substâncias e os tipos de substâncias. Uma representação gráfica de tudo que já havia sido aprendido deveria ser criada, demonstrando uma ordem lógica de aprendizado e posteriormente os estudantes deveriam escrever a definição de cada termo aprendido. Vamos observar, conforme a figura 2, a representação gráfica criada pelos três grupos de estudantes:

Figura 2 - Representação gráfica dos grupos 1, 2 e 3, respectivamente, na ordem de cima para baixo
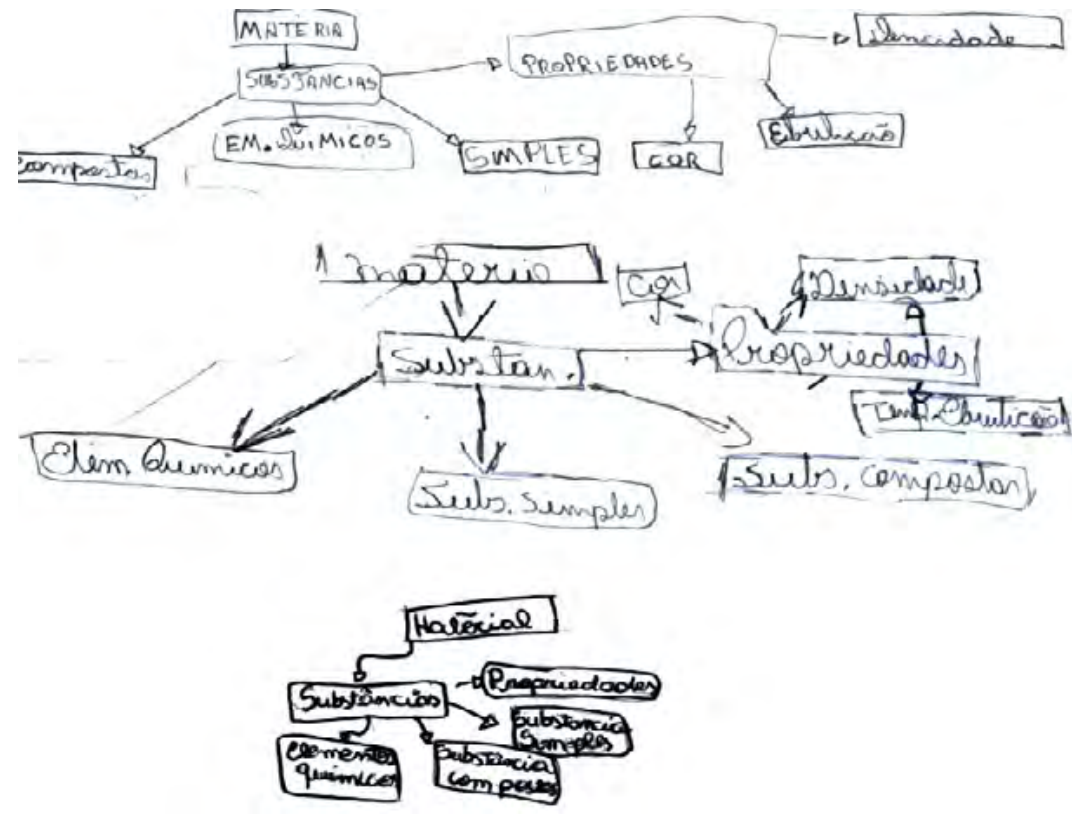

Fonte: SILVESTRE, 2017, p. 104.

Para esta ação, a maior dificuldade encontrada pelos estudantes foi compreender o que seria essa representação gráfica, a professora precisou abrir o próprio livro didático utilizado em sala de aula para explicar e mostrar vários exemplos de esquemas e representaçóes gráficas que explicavam de maneira didática os conteúdos em química. 
De todas as açóes realizadas pelo experimento esta foi a que mais caracterizou a evolução e formação do pensamento teórico sobre materiais e substâncias. Isso pode ser explicado pela própria maneira da criação da representação gráfica desenvolvida pelos estudantes. Pelo modelo convencional geralmente utilizado pelos professores em sala de aula e que aparece nos livros didáticos, a explicação sobre materiais e substâncias sempre parte de modelos e exemplos particulares para se chegar à ideia geral, ou seja, para aprender sobre uma substância o estudante inicia por exemplos de fórmulas de substâncias.

Através do experimento didático fundamentado no ensino desenvolvimental, conseguimos fazer o trabalho inverso, sendo possível observar na figura 2 a representação criada pelos três grupos contemplando uma organização do pensamento, partindo-se do conceito de material (ideia geral) até chegar-se ao conceito de elemento químico (ideia particular), (SILVESTRE, 2017).

$\mathrm{Na}$ ação 4, a proposta segundo o ensino desenvolvimental é a construção de um problema específico (tarefa particular) que pode ser resolvido mediante aplicação do modelo geral do conceito. Para isto os estudantes deveriam resolver dois problemas particulares relacionados ao conteúdo de materiais e substâncias. As tarefas ou atividades particulares foram pensadas de acordo com o desenvolvimento das açóes anteriores, além da maneira que o ensino de Química é cobrado nas avaliaçóes nacionais.

Os três grupos de estudantes conseguiram acertar em 100\% as atividades particulares. $\mathrm{O}$ sucesso na resoluçáo dessas atividades pode ser explicado principalmente pela dedicaçáo e atençáo da professora pesquisadora, que várias vezes acompanhou os grupos, orientando sempre a leitura e fazendo questionamentos que levassem os estudantes a descobrir o caminho para as respostas (SILVESTRE, 2017).

A penúltima ação do experimento foi proposta já pensando na tarefa principal, ou seja, na ação 6 (desenvolvimento da tarefa principal, produção do minidocumentário). Na ação 5, a orientação segundo Davidov (1988) é fazer o controle da ação de aprendizagem do próprio aluno em relação às ações anteriores. $\mathrm{O}$ objetivo da aprendizagem para essa ação foi verificar se houve a aprendizagem do conceito teórico através das açóes de estudo realizadas pelos alunos na solução da tarefa.

Nesse momento os estudantes deveriam iniciar o roteiro e planejamento do documentário a ser realizado a respeito dos conceitos aprendidos sobre materiais e substância. Infelizmente, por questóes de prazo e cumprimento 
do planejamento do experimento em acordo com a escola, foi nesta ação o último encontro presencial. A professora pesquisadora orientou os estudantes sobre a produção do minidocumentário chamando atenção para todas as açóes propostas por Davidov (1988) já desenvolvidas no experimento didático.

$\mathrm{Na}$ última ação, devido à situação já explicada anteriormente, os grupos foram orientados via e-mail e WhatsApp para a produção do minidocumentário. Dos três grupos, apenas dois enviaram o minidocumentário conforme a proposta do experimento. $\mathrm{O}$ único grupo que não enviou argumentou ter problemas na organização e planejamento dos participantes, entre outros fatores.

Os vídeos analisados pela professora pesquisadora demonstraram insegurança por parte dos estudantes ao relatar o que haviam planejado e organizado sobre o pensamento teórico a respeito do conteúdo materiais e substâncias. Tal fato pode ser explicado pela maneira como expressaram este pensamento, alguns, por exemplo, leram o roteiro planejado, outros expressaram o pensamento superficialmente.

Apesar dessas dificuldades, percebemos que uma das orientaçôes mais importantes de acordo com o ensino desenvolvimental foi cumprida pelos estudantes, houve a formação do pensamento teórico através do núcleo conceitual, evidenciado pelo trânsito do pensamento universal sobre materiais e substâncias para o pensamento particular, pela percepção das propriedades e características das substâncias e dos elementos químicos (SILVESTRE, 2017).

\section{Considerações finais}

A tomada de consciência de cada ação e a motivação foram sem dúvida os componentes fundamentais para que as seis açôes fossem realizadas com sucesso. Foi perceptível o desenvolvimento do pensamento teórico não só pelo resultado apresentado no caderno de respostas do experimento, mas também pelo que os estudantes demonstraram na interação entre as falas e questionamentos.

Nas açóes 2 e 3 do experimento foi perceptível o maior desenvolvimento do pensamento teórico que os estudantes não tinham antes do experimento, a partir da criaçáo de modelos e representação gráfica conceitual. Outra característica importante perceptível no decorrer da realizaçáo do experimento foi o domínio da linguagem científica utilizada para o aprendizado do conteúdo materiais e substâncias, que foi formada a partir do desenvolvimento do pensamento teórico. 
Acreditamos que a pesquisa fundamentada no ensino desenvolvimental pode trazer significativas contribuiçôes para o ensino da Química, evidenciado na formaçáo de um pensamento criativo construído a partir do processo histórico sobre o conteúdo materiais e substâncias, o que caracterizou maior autonomia dos estudantes perante a resolução de situaçóes-problemas e argumentaçôes exigidas na relação do processo ensino-aprendizagem.

\section{REFERÊNCIAS}

DAVIDOV, Vassíli Vassilievitch. Análisis de los principios didácticos de la escuela tradicional y posibles princípios de enseñanza en el futuro próximo. In: SHUARE, M. La psicología Evolutiva y pedagógica em la URSS. Antologia, Moscú: Editorial Progreso, 1987. p. 143-155.

Problemas do Ensino Desenvolvimental - a experiência da pesquisa teórica e experimental na psicologia. Texto traduzido do espanhol por José Carlos Libâneo e Raquel A. M. da Madeira Freitas, para uso didático, na disciplina: Didática na perspectiva histórico-cultural, no PPGE da Universidade Católica de Goiás. Moscú: Editorial Progreso, 1988.

. Tipos de generalización en la enseñanza. Havana-Cuba: Pueblo y Educación, 1982.

DAVYDOV, V. V.; SLOBÓDCHIKOV, V. I.; TSUKERMAN, G. A. O aluno das séries iniciais do ensino fundamental como sujeito da atividade de estudo. Journal of Russian and East European Psychology, v. 41, n. 4, jul./aug. 2003, 12 páginas. Tradução para o português realizada pelo Grupo de Pesquisa Implicações Pedagógicas da Teoria Histórico-Cultural da Unesp/Marília.

LEONTIEV A. N. The Fundamental Processes of Mental Life. Journal of Russian and East European Psychology, v. 43, n. 4, p. 72-75, july-august 2005.

LIBÂNEO, José Carlos. A teoria do ensino para o desenvolvimento humano e o planejamento de ensino. Educativa, Goiânia-GO, v. 19, n. 2, p. 353-387, maio./ago. 2016.

ROSSI, Adriana Vitorino; MASSAROTTO, Alexandra Maria; GARCIA, Fabiana Burgos T;; MARCO, Inara Lilian Gabrielde; CURRALERO, Isabel Cristina; TERRA, Juliana; CORREA, Silvana Zanini. Reflexóes sobre o que se ensina e o que se aprende sobre densidade a partir da escolarização. In: ENCONTRO NACIONAL DE ENSINO DE QUÍMICA (ENEQ), 14, 2008, Curitiba. Anais... Curitiba-PR, 2008. Disponível em: http://www. quimica.ufpr.br/eduquim/eneq2008/resumos/R0034-2.pdf.

SILVESTRE, Andréia Andreóli. A formaçáo do pensamento teórico no ensino desenvolvimental: contribuiçôes para o ensino de Química. 2017. 126f. Dissertaçâo (Mestrado)Programa de Pós-graduação em Educação da Universidade Federal de Goiás, Goiânia, 2017.

VYGOTSKY, L. S. A Construçáo do Pensamento e Linguagem. São Paulo: Martins Fontes, 2001. 